\title{
The Research of Uncovered Interest Parity and Monetary Policy
}

\author{
$\mathrm{Li} \mathrm{Li}$ \\ The Department of Finance \\ Fuzhou University of International Studies and Trade \\ Changle, China \\ 26061545@qq.com
}

\author{
Gang-Ping Lin \\ The Department of Finance \\ Fuzhou University of International Studies and Trade \\ Changle, China \\ 1091365769@qq.com
}

\begin{abstract}
This article introduces the theory of uncovered interest parity and describes the relationship between monetary policy and the UIP theory. The UIP means that the expected rate of depreciation of domestic currency against one foreign currency is equal to the interest rate differential in the two countries. This article will demonstrate the theory of UIP with some past econometric tests and discuss whether this theory can hold in different time horizons. Then, how the UIP influences the monetary Policy will be showed in the subsequent part. The UIP is more important in the economic analysis perspective than in the exchange rate market. The simple UIP condition could not be an efficient predictor in the open economy, but its usefulness in international finance researches is obvious.
\end{abstract}

Keywords-uncovered interest parity; monetary policy; limitations; open economy

\section{INTRODUCTION}

The uncovered interest parity theory is a significant basic building block for many monetary models of exchange rate determination in the open economies. It states a relationship between the interest rates in two countries and expected changes in exchange rates of the two countries. Specifically, the expected rate of depreciation of domestic currency against one foreign currency is equal to the interest rate differential in the two countries. However, the uncovered interest parity, which is at useless, is usually rejected by the data in the practical testing. It can be tested by regressing the expected changes of the exchange rate. As such, a regression of exchange rate change which obtains the value from interest rate differential should get a slope coefficient of unity and a zero intercept. Nevertheless, the estimated slope is usually negative which means that the higher interest rate leads to appreciate.

This essay will explicate the theory of UIP with some past econometric tests and discuss whether this theory can hold in short-horizon and long-horizon respectively. Furthermore, the article aims to test the practical usefulness of the theory in the open economy. The first step of this essay is to review the past literature to outline the basic concept of the uncovered interest parity theory and synthesize the opinions from different economists in different periods. The next step is to show how the UIP theory derived and how its assumption can hold or not hold in short-run and long-run. The last part of the article is to discuss the relationship between money policies and the rejection of the unbiasedness hypothesis of the UIP.

\section{THE REVIEWS OF PREVIOUS OUTCOMES IN UIP}

Uncovered interest parity is a parity condition representing that the interest rates differential between two countries equals the expected change of exchange rates between the two countries' currencies. If the condition did not exist, the speculators get the arbitrage opportunities to make a profit without any risks. Specifically, if the interest rate in the domestic country is $10 \%$ per year, while the interest rate in the foreign country is $5 \%$ per year, then international investors expect the domestic currency to depreciate by $5 \%$ per year on average. The amount of depreciation would compensate the expected returns on two different currencies denominated assets. If international investors expected the domestic currency depreciation is more than the interest differential, the speculators would wish to borrow in domestic currency and lend in foreign currency. Hence, domestic currency interest rate would tend to rise when the foreign currency interest rate tends to fall until the interest rate differential became the expected change.

The basic setting which is to hold UIP condition continuously is that capital is perfectly mobile and the assets such as bonds in two countries is perfect substitutes. The foreign exchange market is one of the most active financial markets. The net volume of foreign exchange trading the entire world has been estimated to excess $\$ 3$ trillion per day. Because foreign exchange dealing is so much greater in volume than the trading in real goods and services, the foreign exchange markets would be high liquid and efficient.

The importance of UIP conditions has been generally confirmed in the world, it plays as a key role in virtually all the prominent modern modes of exchange rate determination. Which some of the models are used by international organizations to decide the policies. However, the uncovered interest parity theory is usually rejected assuming rational expectations empirically. The forward exchange rates are not consistent with predictors of future spot exchange rates. Hence, the returns of forward speculation should be predictable nonzero.

Many past papers exist discussing reasons for the empirical failure of UIP condition. The first explanation of rejection is that the expectations are irrational. In the expected errors explanation, the risk premium is constant. However, the period studies were unrepresentative or the normal methods of statistic 
study may induce to inaccuracy conclusions. One of the obvious example is that of "peso problem". The Mexican peso in 1955-76 was fixed at a constant rate against dollar by the government, therefore, the peso always sold at $\mathrm{s}$ forward discount. Of course, the interest rates and the forward discount support the prediction of the large depreciation expected by investors. However, the prediction is not consistent with the real 1955-75 data and leads Mexican to a terrible situation.

The second reason of the rejection of the UIP condition is that time-varying risk premium are present. The interest differential or forward discount could not be explained as a pure expectation of the change in the exchange rates if investors in foreign exchange markets are not risk neutral. In particularly, the interest rate differential is the sum of a risk premium plus the expected change in the exchange rates. Furthermore, a negative correlation between expected depreciation and the risk premium should be considered: higher expected inflation in the domestic country might be related with greater expected domestic currency depreciation and increased risk of domestic assets.

Even though the empirical failure of the uncovered interest parity theory has been a complex problem to international financial researchers. The UIP is both more significant and more enlightening from the economic analysis aspect than the unbiased question of foreign exchange market. It is the fundamental rule of almost all the modern models of exchange rate determination.

Chinn and Meredith (2004) assert a different opinion with the past research that the UIP can be supported by the test using interest rates on long-horizon data ${ }^{[1]}$. The UIP has been rejected in almost all tests using data with relatively short horizons in the past published studies. However, the test which used the data of financial instrument with maturities ranging between five and ten years can get the appropriate parameter in consistent the UIP condition. Nevertheless, Chabound and Wright (2004) argued that the UIP theory can work in extremely short horizons such as overnight situation and got an opposite outcome with previous research ${ }^{[2]}$.

\section{CONCEPT OF THE UIP}

The part starts with the introduction of the covered interest parity which is from the assumption of arbitrage between spot and forward foreign exchange markets. The CIP theory claims that at any time $t$ the international investors can hold assets denominated in domestic currency with the interest rate $\mathrm{R}_{\mathrm{t}}$ or hold assets denominated in foreign currency with the interest rate $R_{t}^{*}$ between times $t$ and $t+1$. Algebraically, the covered interest parity can be expressed as:

$$
1+R_{\mathrm{t}}=F_{\mathrm{t}}\left(1+R_{\mathrm{t}}^{*}\right) \div S_{\mathrm{t}}
$$

Where $S_{t}$ represents the sport exchange rate in units of domestic currency per unit of foreign currency, $F_{t}$ is the forward exchange. The (1) indicates that an investor with unit of domestic should compare the choice of acquiring $1+R_{t}$ units and the choice of $\left(1+R_{t}^{*}\right) / S_{t}$ units of foreign currency, then converting it into domestic currency with $\mathrm{F}_{\mathrm{t}}$. If the two options can get the same return, the CIP condition holds. If (1) does not hold, the investors can get the profitable market arbitrage opportunities without risk. By manipulating (1), as a approximation:

$$
\left(F_{\mathrm{t}}-S_{\mathrm{t}}\right) \div S_{\mathrm{t}}=R_{\mathrm{t}}-R_{\mathrm{t}}^{*}
$$

Condition (2) represents a risk-free situation that holds regardless of international investors. The UIP theory combines the CIP condition with the driven exchange rates assumption. Investors leave their foreign currency positions uncovered at time $t$ and reconvert them into domestic currency until time $t+1$ at the spot exchange rate $S_{t+1}$ rather than $F_{t}$. The value of $S_{t+1}$ is unknown, hence, the UIP condition postulates that the return on the domestic currency asset equals the return on the foreign exchange with the expected exchange rate $E_{t}\left(S_{t+1}\right)$.

From condition (1),

$$
1+R_{\mathrm{t}}=E_{\mathrm{t}}\left(S_{\mathrm{t}}+1\right)\left(1+R_{\mathrm{t}}^{*}\right) \div S_{\mathrm{t}}
$$

Then,

$$
\left[E_{\mathrm{t}}\left(S_{\mathrm{t}}+1\right)-S_{\mathrm{t}}\right] \div S_{\mathrm{t}}=R_{\mathrm{t}}-R_{\mathrm{t}}^{*}
$$

The (4) claims that the UIP assumption adds an dynamical elements to the CIP condition by presuming a relationship between the observed variables at time to and the expected value if the spot exchange rate at time $t+1$. Furthermore, if markets are efficient, arbitrage will have eliminated any profit opportunities. Then, the forward rate $F_{t}$ should equal the expected future spot rate $\mathrm{S}_{\mathrm{t}+1}$. In other words, the (2) and (4) are identical in the efficient market hypothesis.

\section{EMPIRICAL EVIDENCES OF THE UIP HYPOTHESIS}

The UIP condition is more difficult to test than the UIP assumption because of the expectations of future exchange rates can not be directly observed. Hence, the UIP condition can be tested empirically by regressing the expected change of the sport exchange (Christensen, 2000) ${ }^{[3]}$. The future spot exchange rate at time $\mathrm{t}+1$ will equal the value expected at time $t$ with an error term that is no relationship with all observable information at time $t$.

$$
S_{\mathrm{t}+1}=F_{\mathrm{t}}+\mathrm{u}_{\mathrm{t}+1}
$$

Which $\mathrm{u}$ is the error term, hence

$$
S_{\mathrm{t}+1}-S_{\mathrm{t}}=F_{\mathrm{t}}-S_{\mathrm{t}}+\mathrm{u}_{\mathrm{t}+1}
$$

The UIP assumption can be tested by estimating the values of the parameters in the specific form (Flood \& Rose, 2002).

$$
\left(S_{\mathrm{t}+1}-S_{\mathrm{t}}\right)=\mathrm{b}_{0}+\mathrm{b}_{\mathrm{l}}\left(R_{\mathrm{t}}-R_{\mathrm{t}}^{*}\right)+\mathbf{u}_{\mathrm{t}+1}
$$

The null hypothesis is $b_{0}=0, b_{1}=1$, hence, the realized depreciation of the spot rate equals the interest differential plus a random error term $u_{t+1}$. From (6), the forward discount, which is the difference between the current forward and spot exchange rate, replaces the interest differential. By arbitrage, the forward discount will equal the interest differential in the risk neutrality and rational expectations.

The past researches have tested the unbiasedness hypothesis to found that the coefficient $b_{1}$ is less than one, evenly, less than zero. The survey by Froot and Thaler (1990), 
found the average parameter of $b_{1}$ across some 75 published estimates is -0.88 . A few are positive, however, no one is greater than the null hypothesis of $b_{1}=1$. The situation is hard to explain ${ }^{[4]}$. In (7), the size of the error term is an issue for the test. It has been known that the interest differentials might explain just a small part of changes in exchange rates. Dmowitz and Hakkio (1985) argues that $b_{1}$ which is smaller than 1 because of a time-varying risk premium on foreign exchange market ${ }^{[5]}$. If investors are risk inverse for domestic assets in foreign exchange markets, they need higher interest rate to hold the assets than the risk neutral investors. In particularly, $b_{1}<1$ indicates that 1 percent increase in the interest differential leads to a less than 1 percent depreciation in the value of domestic currency. Furthermore, the condition of $b_{1}<0$ is more extreme which implies that the variance of the risk premium is greater than the variance of interest differential and the variance of the expectation of depreciation, in addition, the covariance of the risk premium and expected depreciation is negative ${ }^{[6]}$.

Even if the empirical evidence obviously rejects the unbiasedness hypothesis of the UIP at the prediction periods which is up to one year, the situation is better at prediction horizons of five to twenty years. The results of the estimates with long-horizon data in the research from Chinn and Meredith (2004) representing a surprising and obvious contrast to the short-run results in past articles. The estimated slope coefficient $b_{1}$ is positive and four of the six values lying closer to one than to zero. This result is also consistent with the earlier conjecture of Froot and Thale (1990) that the united interest parity condition might work better at longer periods.

An important relationship between money policies and interest rate has been neglected in almost all the past researches. The monetary policy authorities manage interest rate to keep the economic development in a design path. In the short horizons, money policy responses the shock in exchange rate markets which leads a negative correlation between interest rates and exchange rates, contrary to the unbiasedness hypothesis of the UIP condition. Basically, the monetary authorities tend to resist rapid changes in exchange rates in both domestic and foreign countries with the main instrument of money policy which is the short-term interest rate. The estimates of $b_{1}$ in the equation (7) may be biased by the influence of the money policy.

By contrast, in the long run, interest rates and exchange rates are decided by the macroeconomic setting of the model. Thus, it is more coincident with the conventional UIP condition. In specific, an inflation shock raises the short-horizon interest rate. Result in the exchange rate initially appreciates in the first period followed by depreciation in subsequent periods. The relationship between the lagged interest rates and the change of the exchange rate is consistent with the UIP theory in the subsequent periods after the first period. It indicates that the current effects of exchange market shocks which are induced by higher interest rate will fade over long horizons, and then the results are accordance with the UIP condition.

\section{CONCLUSION}

The uncovered interest parity assumption is a classic topic in international finance, an important block of most monetary models if exchange rate determination in the open economy. The rejection of the unbiasedness hypothesis of the UIP condition has been a puzzle to researchers in the international finance field. The economists interpret the puzzle with some explanations. The first is that the expectations in the hypothesis are irrational with the unrepresentative samples or in a special period. The other explanation is the time-varying risk premium, which is accepted by most economists that the investors in the UIP is risk averse rather than neutral to produce the interest premium. This essay focuses a different illustration from McCallum (1994) that money policy from monetary authorities leads to the biased situation [7]. Chinn and Meredith (2004) explain the puzzle with a new direction; they claim that the UIP can hold in the long-horizon even though there are many "noises" in estimates with long-run data. Furthermore, it should not be efficient in short horizons.

However, there are many limitations in the researches. The risk premium explanation does not identify the proportion of the risk averse people in the investors and the risk averse degree ${ }^{[8]}$. The irrational sample interpretation could not be suitable in explaining all the past papers said the rejection of UIP. Chinn and Meredith's model did not identify a specific length of the period about short-horizon and ignored the "noises" in the long-horizon. Hence, there are problems that remain to be explored ${ }^{[9]}$.

The explanations should not give an explicit answer to the puzzle of rejection of unbiased hypothesis of UIP. However, the UIP is more important in the economic analysis perspective than the biased question in the exchange rate market. Even though, the simple UIP condition could not be an efficient predictor in the open economy, its usefulness in international finance researches is obvious.

\section{ACKNOWLEDGEMENT}

This research is financially supported by the Education Department of Fujian Province (Project number: JZ160491).

\section{REFERENCES}

[1] M. D. Chinn and G. Meredith, "Monetary policy and long-horizon uncovered interest parity," IMF Staff Papers, 2004, 51, 409-430.

[2] A. P. Chaboud and J. H. Wright, "Uncovered interest parity: it works, but not for long," Journal of International Economics, 2005, 66(2), 349362 .

[3] M. Christensen. "Uncovered interest parity and policy behavior: new evidence,” Economics Letters, 2000, 69(1), 81-87.

[4] K. A. Froot and R. H. Thaler, "Anomalies: Foreign Exchange," The Journal of Economic Perspectives, 1990, 4, 179-192.

[5] I. Domowitz and H. Craig, "Conditional variance and the risk premium in the foreign exchange market," Journal of International Economics, $1985,19,47-66$

[6] E. F. Fama, "Forward and Spot Exchange Rates," Journal of Monetary Economics, 1984, 36, 697-703.

[7] B. T. McCallum. "A reconsideration of the uncovered interest parity relationship". Journal of Monetary Economics, 1994, 33(1), 105-132.

[8] R. P. Flood and A. K. Rose, Uncovered Interest Parity in Crisis. IMF Staff Papers, 2002, 49, 252-266.

[9] E. Fujii and M. Chinn, "Fin de siècle Real Interest Parity," Journal of International Financial Markets, Institutions and Money, 2001, 11, 289308. 